\title{
Beneficial appropriation and corporate exploitation: Exploring the use of ethnographic methods in art, craft and design
}

\author{
By Hamid van Koten
}

\begin{abstract}
Born in Rotterdam Hamid van Koten came to Britain to study Middle and Far Eastern philosophy. He also acquired practical skills as a furniture maker, and in 1993 he graduated from Glasgow School of Art in Product Design. Since then he has been the director of the VK\&C design consultancy and has worked on a wide range of projects, including industrial, exhibition, interior, and architectural design as well as public arts commissions. He has exhibited in the UK and Internationally and has won a number of awards. His work has been much published. He now lectures in Cultural Studies at the School of Design, University of Dundee.
\end{abstract}

\begin{abstract}
Recently there has been a move towards incorporating ethnographic practices into the research phase of the design process. Groundbreaking work has been done by design consultancies like IDEO (2001), and by trend-predictors such as The Future Laboratory. Large corporations (BMW, Philips and Mark \& Spencer) employ ethnographic methods to gather data on the use of their products, their retail outlets, and their customer's relationship with their brand identity. Video diaries ethnographic fieldwork, and co- design tool kits (Sanders, 2002) are rapidly becoming the new means for product and service development.
\end{abstract}

Though there are many advantages to the incorporation of anthropological perspectives and working methods into the design environment, (e.g. providing the design team with a more holistic and more meaningful approach to problem formulation) there is also a need to look critically at this migration of practices. This paper will explore the re-contextualisation of these methods and will examine if this is merely a further refinement of strategy, employed by a corporate class, to maintain and stimulate the late-capitalist mode of consumption. These methods may thus be the latest addition to the array of marketing tools, co-existing with the traditional focus group, the market research questionnaire, concept testing, customer satisfaction studies, and so on.

The paper will also seek to compare and contrast this migration into the design profession with the application of ethnographic approaches to identity and place as employed by arts and crafts practitioners. Both of which disciplines, unlike design, are much more aligned with the transparency of cultural production of pre-industrial settings. Ethnographic methods provide powerful means for designers, artists and craft people alike, to interpret and understand specific social networks and symbolic structures, and they are able to translate these into 
meaningful visual expressions of personal and community identity. The paper will use a few examples from design and art in order to illustrate the diverse uses of ethnography; including a large community arts project, completed by the author, at Ullapool, a small fishing village on the West coast of Scotland.

\section{Ethnography in commerce}

The use of ethnographic methods in commercial settings can now trace a history of at least 20 years. When we speak of ethnography in this context, the primary aim of its application lies in utilising the data acquired, in order to understand how humans form meaningful relationships between themselves, objects and their environment. However the ethnographic data gathered is not necessarily recorded in writing for further analysis or indeed disseminated via writing, but the insights gained are applied to a process of production. Ethnography in a commercial context, or one of artistic production, might often employ other means for recording data distinct from writing, such as video, photography, akin to visual anthropological methods, but also - as we shall see - more interactive means for co-creation.

Reluctant at first, industry wondered what the value of ethnographic data collection might be, but rapidly began to realise that methods like these are a powerful way to access what people value and find meaningful in their lives. At the Harvard School of Business ethnographic research is now advocated as an essential component of the commercial environment (Nussbaum, 2006). Education elsewhere is beginning to follow suit, and so, as ethnographic methods are likely to become the new competence to be instilled in budding designers, marketers and managers, questions about these methods and their effectiveness need to be considered.

\section{Changes in the commercial process}

It was not until the late 1970s that company managers began to realise that apart from marketing, the design of products and services has a significant impact on sales. Suddenly then there was an influx of management theory covering the subject of design, how it should be managed, used as a strategic tool, be part of an overall company identity and so on. Since then there has been a strong emphasis upon the rationalisation of design activity. Design was no longer a form of applied art but a structured process with logical stages, and should be managed as such (Design Council, 2007). Whilst setting up as a design consultant in the 1990s I did some advisory educational work in secondary schools. During this time a number of educational directives were advocating design skills and grasp of design process as core competencies, the teaching of which was to be embedded in the national curriculum. In secondary schools, the teaching of design skills became a battleground between the arts departments, 
who claimed it historically, and the crafts and technology departments, hungry - it seemed - for this new knowledge. Home economics also was persuaded to take on board the design process as an important curriculum component.

The design process is often visualised as a series of stages: Research, concept, development, final product, and implementation. Presented in this way, the design process is an almost mechanical exercise and has, arguably, descended to us from the Bauhaus, which saw design as the application of artistic skills to a growing manufacturing culture (Gagliardi, 2007). In keeping with the Modernist paradigm of social and egalitarian distribution, the Bauhaus focussed on production - its processes, and the suitably geometric formal language, and its material capabilities - as a means to serve all people and to address universally all needs. Since the 1950s this model has almost reversed itself, from a production focus to a consumption/market focus. In ou rpost-industrial culture where the emphasis has shifted to the production of services and knowledge it is particularly the early, research stage of the design process that has come to the forefront. No longer do designers start out with a social, universal conception and then utilise available resources and industrial processes to benefit a large market with perceived equalitarian needs, but now the initial starting point has become a specific submarket or even specific individuals within a designated submarket group. In this new model of business practice a critical understanding of the target group is thus fundamental for designers (see Figure 1).

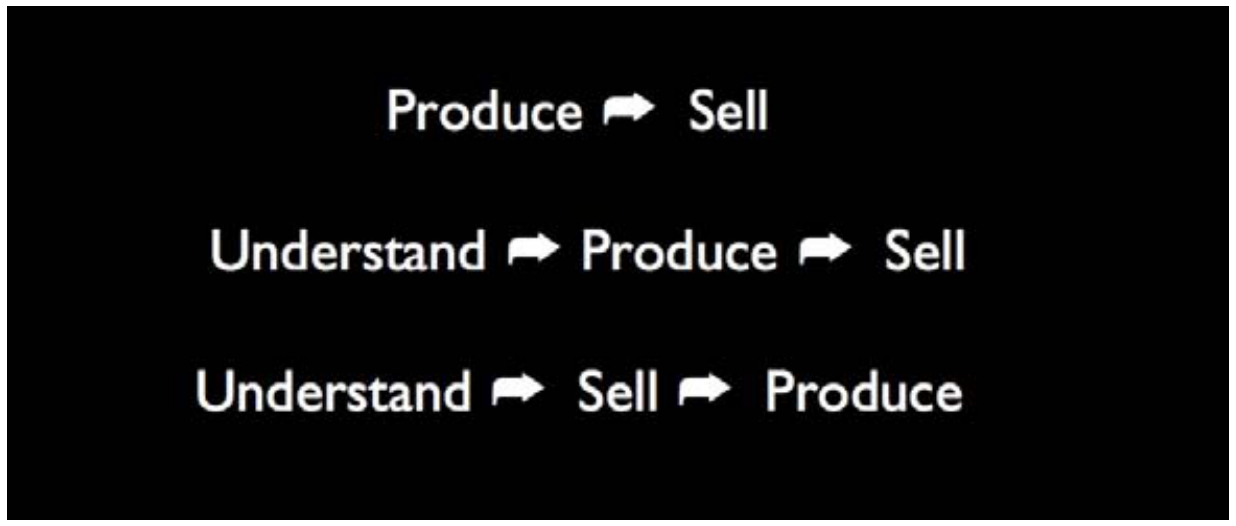

Fig. 1. Changes in the commercial process. A new breed of companies (e.g. Dell Computers) has emerged which assemble or manufacture products only after these have been ordered and paid for (Image VK\&C Partnership, 2006.)

The latter half of the previous century moved from what were a rather crude, but effective set of demographic groupings, to the development of differentiated markets tied to differentiated lifestyles. Demographic profiling based upon income brackets, class and professional status was overtaken by psychographic profiling and lifestyle analysis. Since then lifestyle groupings have further fragmented into loose dynamic clusters of individuals with overlapping value sets. It is these values sets that are now important drivers in product development and design (Dodd, 2001). 
In a globalised economy fewer and fewer corporations are actual producers. For many companies their main operating activities are marketing, distributing and selling. Companies nowadays must engage in cultural analysis in order to gain an understanding of what codings are required to match their products to consumers. By codings I mean the semiotic level of objects, the values that the objects signify through their appearance and context (Krippendorff, 1989). Nowadays designers as well as design students acquire an understanding of the markets and the users for which they make proposals. Designers gain a perspective on how people will engage with and make sense of a product. An understanding of end users, how they think, feel and act, has become vital to business success (Sanders, 2006). Parallel with this evolution of the commercial process, there have emerged analytical tools for understanding the consumer - door to door polling, the focus group, lifestyle questionnaires, user testing, consumer satisfaction surveys, online surveys, the supermarket loyalty card and so on. These are all progressively more sophisticated forms of market research. This type of consumer understanding was traditionally gained quantitatively, through marketing questionnaires, and more qualitatively by focus groups. But these methods are beginning to show their limitations and no longer appear to function. Market research questionnaires can reach only so far. People reply according to how they imagine their behaviour, and according to how they believe they should respond (Raymond, 2003). ${ }^{1}$

We can question people about concrete characteristics e.g. the price of a product, its size, or the speed with which it operates, ease of use, and so on. Symbolic and emotional associations are much harder to capture. Responses to these are often sub- and unconscious and more difficult to articulate. Even focus groups can only provide limited insights. ${ }^{2}$ The artificiality of the focus group, its setting and make up and its specific intention all limit the flow of information. But apart from that there are certain things people will simply not talk about, no matter how relaxed the focus group atmosphere might be. To give an example of this: in recent years the Miller Brewing Co. noticed a significant and inexplicable drop in the consumption of its low alcohol product Miller Lite. They asked ethnographers to do field research by visiting clubs and pubs. They observed something that most men might be reluctant to admit to in interview or questionnaire: that it is increasingly women who are influencing what men drink - and women simply were not responding to the traditional masculine cues of the Miller ads. Consequently we have seen Miller Lite campaigns change from what was a very macho oriented approach (extreme sports, telling tales, female catfights) to a softer and more inclusive approach, in order to address these "new emerging bar cultures" (McCracken, 2006).

1 In The Order of Simulacra, Baudrillard suggests that polls and questionnaires can no longer operate as a means for gathering genuine responses, he says: "[...] it is impossible to obtain a nonsimulated response to a direct question [...] there is total circularity in every case: those questioned always behave as the questioner imagines they will and solicits them to."

2 For a critique on the focus group see e.g.: http://www.artsci.com/areascritread.htm 
To stay with Miller, previously the company conducted an extensive ethnographic study into its consumer base. This was in order to find out what the key characteristics are of a typical Lite drinker, and especially what distinguishes them from drinkers of Miller's main competitor Budweiser. An anthropological analysis of recorded male drink behaviour found that Miller Lite drinkers form a social bond around the drinking behaviour "Miller is favored by groups of drinkers, while its main competitor, Bud Lite, is a beer that sells to individuals." If we look at their advertising campaigns then we can see this clearly reflected in the way the respective brands are promoted.

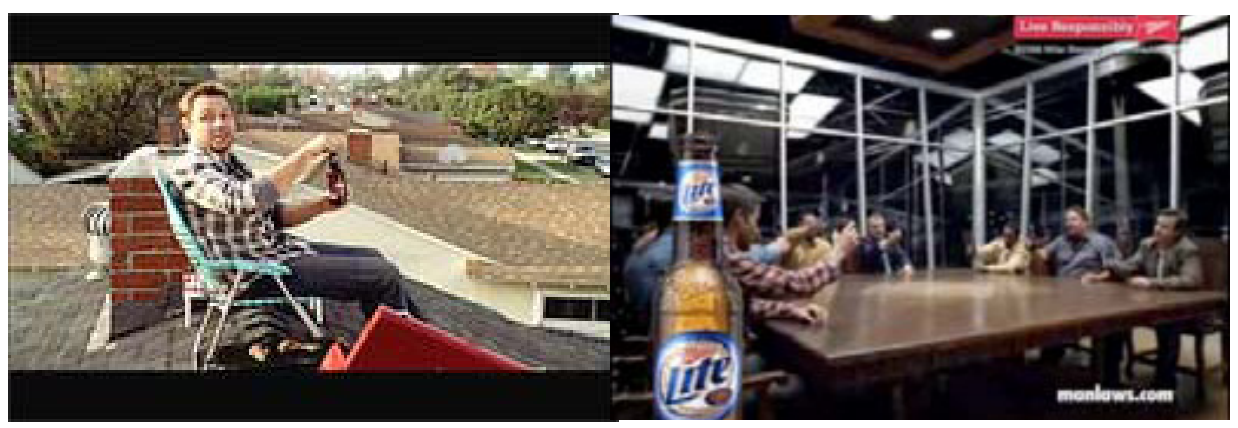

Fig. 2. Budweiser (left) promotes its Lite brand by depicting individuals in drinking scenarios, whereas Miller targets group drinkers by showing 'male bonding rituals'.

(Images: Budweiser, Miller, 2007, no copyright infringement intended.)

This example demonstrates that, although quantitative surveys and focus groups are still in use, corporations that truly seek to understand the behaviour of their consumers have found their way to these observational forms of research, appropriated from the ethnographic and anthropological disciplines. If corporations can understand the rituals and values their potential consumers respond to, than they will be able to utilise this in their brand communications via advertising and promotion.

As anthropology deals primarily with the understanding and decoding of human behaviour in order to uncover the symbolic relationships between humans and their environment, the marketing promotion and design of products would seem to be its ideal territory. Recently then there has been a new momentum toward the practical application of ethnographic methods in both the early and later stages of the design process (Sanders, 2006).

\section{Anthropology versus Design Ethnography in a design context}

The methods by which anthropologists penetrate deeper into our symbolic worlds are somewhat contrary to the skills we traditionally equip designers with.

3 For more details on this particular study see: http://www.fastcompany.com/magazine/81/ everymove.html [accessed: 15/12/06]. 
Designers are generally keen to initiate close involvement with the subject of study and like to offer up solutions, backed with (at times opinionated) rhetoric. They will ultimately need to achieve some sort of conclusion by a certain deadline and for a certain price. Ethnographers - though constrained by time and money - are traditionally trained to do the opposite and to avoid too much close exchange with subjects of study (although inevitably this does happen) or at least to be aware of the 'skewing' that may result from this involvement. Ethnographers are trained to neutralise their impartiality by means of formal methodology. (For a discussion and critique on this see: Fine, 1993.) For many designers this may well be a counter-intuitive way of working, as design is still generally understood and taught as a problem solving activity. Designers therefore tend to operate in a solution-focussed mode, often jumping to conclusions before really taking stock of all the available information. Ideas spring up in the designer's imagination, disrupting what ideally would be a neutral and observational mode of engagement. Furthermore the information gathered by ethnography is much more fuzzy than the research material gathered by designers from their initial investigation. Designers tend to be interested in data they can apply in the short term, in opposition to ethnography where everything is relevant in the first instance and is analysed in a wide context. Thus the motives for observation and data collection are somewhat different for an ethnographer from those of a designer.

As Paul Skaggs (2005) suggests:

\begin{abstract}
Observational research is similar to ethnography in process, but the results the designer is looking for are different than what the anthropologist is looking for. The ethnographer is looking for generalities; the designer is looking for specifics. The ethnographer is concerned with analysis; the designer is concerned with synthesis. The ethnographer is avoiding making judgements; the designer is required to make judgements; the ethnographer looks at prolonged activity; the designer requires information quickly.
\end{abstract}

Skaggs comments highlight some of the problems with the commercialisation of the ethnographic method.

In the case of the female influence on male beer drinking behaviour, discussed above, an anthropologist would no doubt prefer to assess the significance of this data within a much wider and longer-term context, and with regards to human relationships - questioning a number of things, such as whether there are social shifts underlying these changes in drinking behaviour? Are those shifts significant with regards to gender relations? Do they denote a changed attitude in men towards women or vice versa? Designers and advertisers will be more interested in what the implications are for the market and the marketing of the product. They might ask very different questions like: Should we change the way we position our products in the market place? Do we need to change the text and imagery of our advertising materials, perhaps our labels? Should we even change the shape of the bottle? What should the future pub look like? Perhaps we need to focus on wine bars instead? 
Another example of the application of ethnographic methods in a commercial context is that of HomeLab, a project undertaken by the Dutch electronics company Philips. HomeLab is a comfortable hotel-like environment into which people are invited and where they live with, use, and then share their views on, the latest electronic aids for living. The place is not unlike the Big Brother house, and has been criticised by ethnographers for doing second rate ethnography by avoiding the more 'authentic' home environment. Rather than going into homes of people and installing these new devises, Philips does not seem to take account of the fact that when people are placed in an artificial environment, they are likely to behave in artificial ways (Shaffer, 2005).

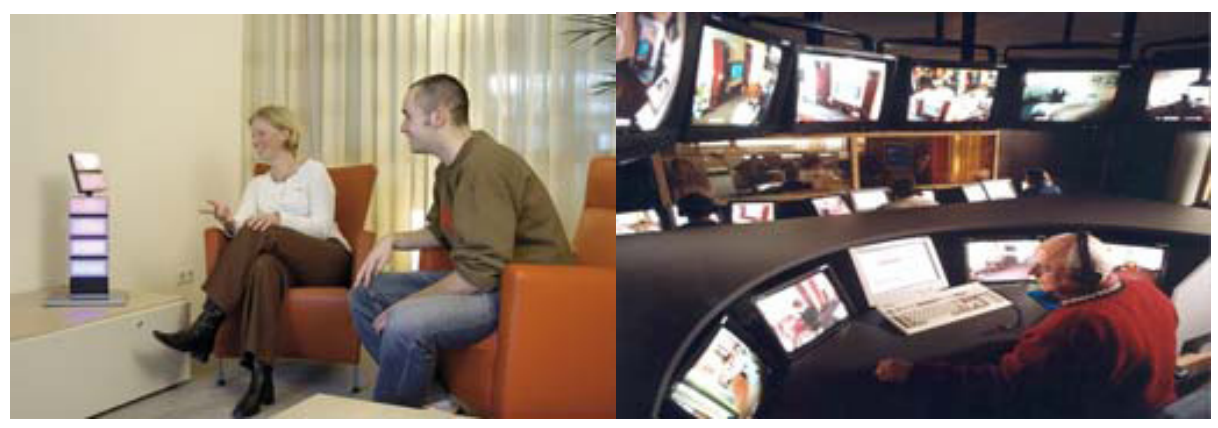

Fig 3. Philips, 2004, (Reproduction permitted). Philips HomeLab. Temporary residents are observed while they test and comment on new electronic products.

Perhaps a more successful example of traditional observational research in action is that of IDEO, the design consultancy that claims to be the first in taking up ethnography as a tool for design development (Kelley, Littman, 2001). When the Bank of America commissioned IDEO to come up with a new concept for a bank account, IDEO utilises a mixed methods approach to research, in the process they commissioned a number of observational studies into how customers used their banks. Through close observation of the selected group ('boomer mothers') the ethnographers noticed that, for speed and ease of calculation, many people round up their pennies to the nearest dollar. They also noticed that this particular group of bank users seemed to find saving very difficult to do. From these observations IDEO proposed an account that gives clients the option to receive their statements automatically rounded up. A further option suggested by the company was that customers could divert the 'change' into a personal savings account or to a charity of their choice. This new "Keep the Change" account proved so popular that in the year after its launch the bank gained 700,000 new account holders and opened 1,000,000 new savings accounts (IDEO, 2006). ${ }^{4}$

4 For more on IDEO's method: http://www.creditunionbusiness.com/html/sales_marketing.html [accessed: 15/12/06] 


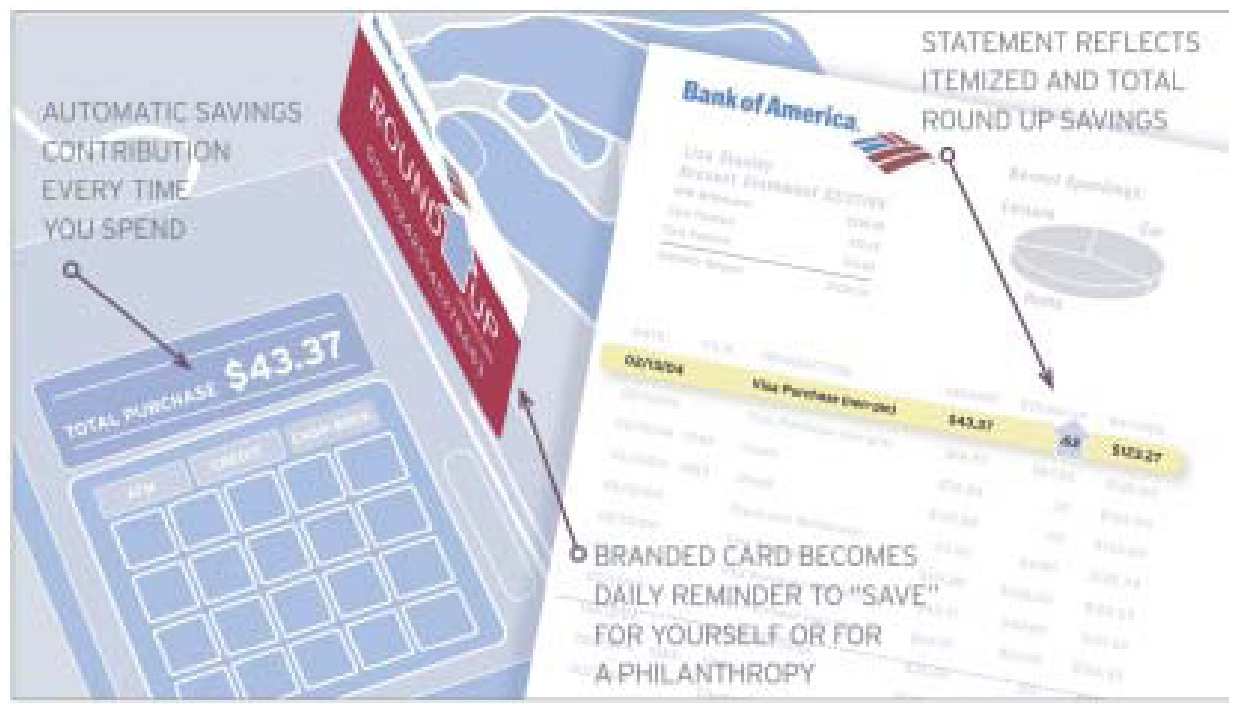

Fig. 4. Keep the Change, IDEO's innovative new bank account. (IDEO, 2006, no copyright infringement intended.)

Another example is the Future Laboratory, a London based trend research consultancy, with an international research network. They do briefings to large corporations on newly emerging consumer behaviour and trends. Much of their research comes via email from a worldwide virtual network. Information is received in response to questionnaires that are then sent back by recipients sometimes with relevant images. The Future Laboratory also engages ethnographers to undertake qualitative research.

Fieldwork - they believe - always wins out over focus group work. This is because in a focus group people speak from memory, which is at best unreliable, whereas observational research allows for direct contextualisation between product and user behaviour (Raymond, 2003).

In 2001 the Future Laboratory was contracted by BMW, who had just bought the British Mini production plant. The German company was keen to explore and understand the 'ordinary' Mini driver, as this was a market very different from that of the traditional BMW customer. They commissioned the Future Laboratory to do an ethnographic study, comparing BMW drivers with drivers of small cars. BMW drivers were interviewed, then provided with a camera and were asked to record visually what they thought important about the car they owned. The images that came back were revealing and contrasted dramatically with how they spoke about the cars. (See Figure 5.) Verbally BMW car owners claimed that their choice of car was all about "spirit, personality, space" (Raymond, 2003, p.189), however the photographs they submitted showed a rather clinical detachment and a rational attitude to the cars. Most images were of "clean hubcaps, pristine engines, streamlined steering wheels, sleek surfaces and 
foldaway tool kits" and with very little reference to people and "paraphernalia that suggest personality, spirit or emotion in the traditional understanding of these words" (Raymond, 2003, p.189).

The Future Laboratory ethnographers similarly recorded the way that small cars were used and found that when questioning 'ordinary' car users they seemed to place very little emphasis upon the meaning of the brand they drove. When asked why they had chosen their car they referred to practicality, convenience, size, and cheapness. Buying a car for the sake of a brand name they perceived as decadent and even ethically irresponsible. However when probed further these drivers all turned out to have an

'ideal' model and brand that they related to, e.g. classic Mini, Morris Minor, VW Beetle and so on (Raymond, 2003, p.192).

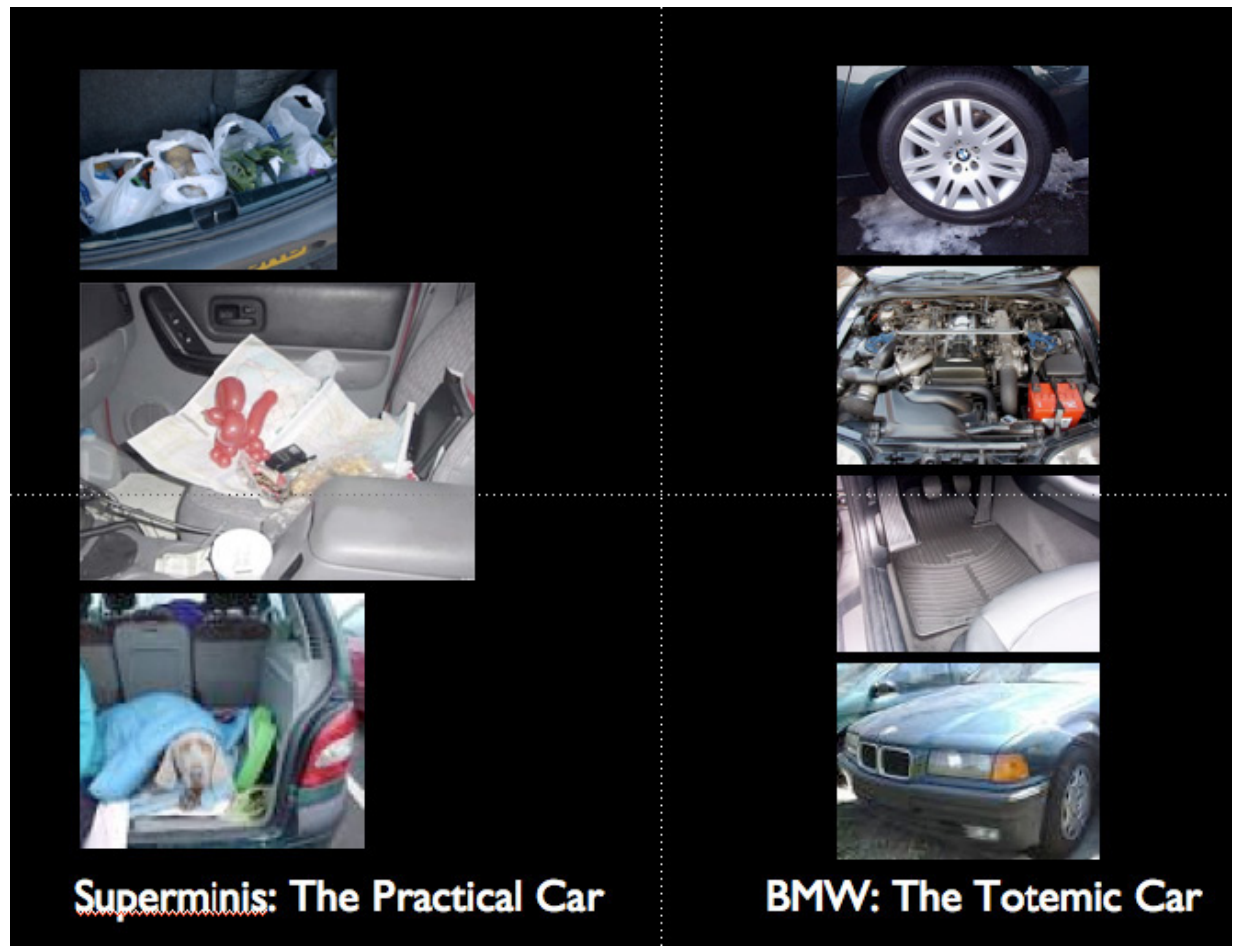

Fig. 5. Photo dairies illustrate the contrast between 'ordinary' car drivers and BMW owners. (No copyright infringement intended.)

This method of researching consumer motivation revealed how large gaps can occur between what people say and what they mean, and furthermore what they do in practice. The Future Laboratory demonstrated that observational research is a means to bridge these gaps and can provide profound insights in how people relate to products. 
In a similar way to some of the other examples already mentioned, the Future Laboratory have also been employed to address negative retail trends such as that of Marks and Spencer, who, in an attempt to address the loss of custom, commissioned the Future Laboratory to investigate its retail environment. Ethnographers were paired up with elderly and disabled shoppers and then followed the consumers from their home environments (having established a knowledge of their existing wardrobes) into the shops in order to understand and identify their specific needs and wants. All was recorded for later analysis. (See Figure 6.) At the end of this research period a whole range of recommendations were made to M\&S in order to achieve a retail environment which would be much more inclusive for the elderly and impaired shoppers.

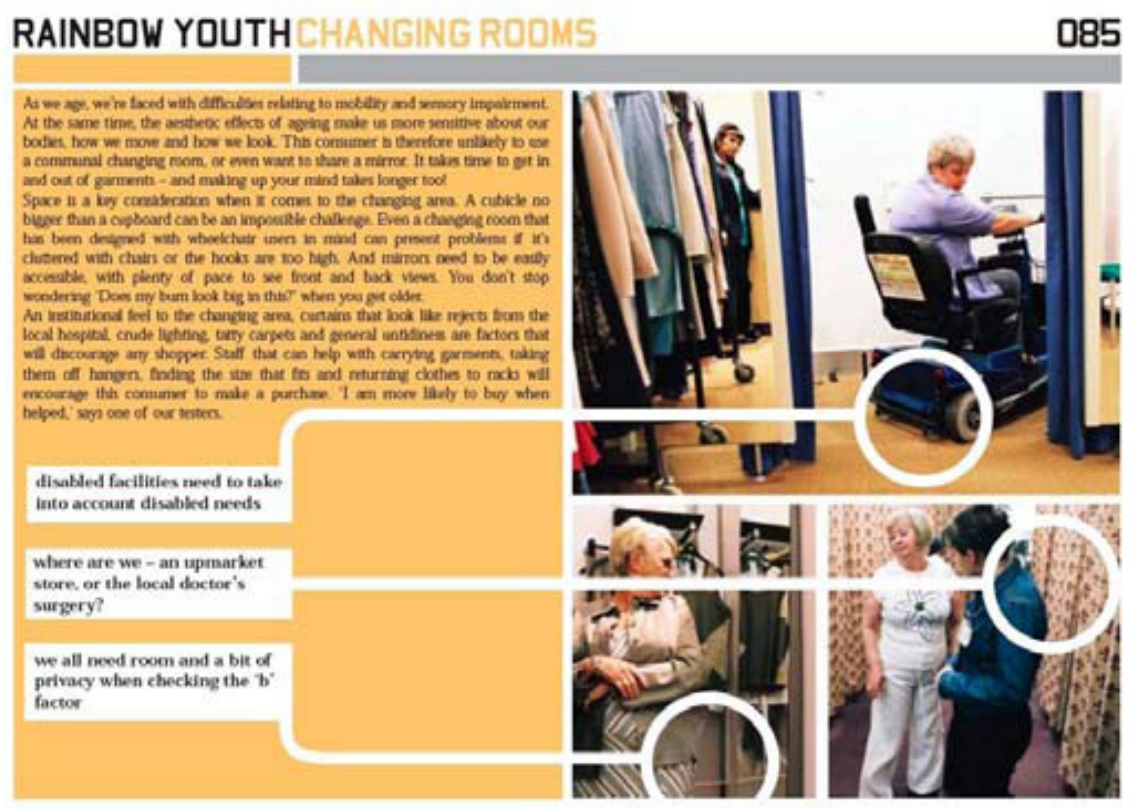

Fig. 6. The Future Laboratory. 2004. (Reproduced with permission.) After analysis of video ethnography many recommendations were made to Marks and Spencer for improvements to their retail environment.

\section{Tools for Conviviality}

The examples provided so far, in effect, treat the consumer as the subject to be designed for. In contrast to this Elizabeth Sanders5another one believes businesses (and designers) need to go one step further. She suggests that we no longer need to just observe what people do, and than design with that in mind, but we need to involve people directly in the design process. People, she claims, no longer want to be treated like consumers but want to be actively and 
creatively involved in new product development. It is this creative dimension of the end user that has been ignored by our industrial culture and, in the future, designers, she suggests, will merely provide 'scaffoldings' (Sanders, 2002) for end users to construct their own products. To enable this co- or participatory design process she has developed a series of tool kits (see Figure 7).

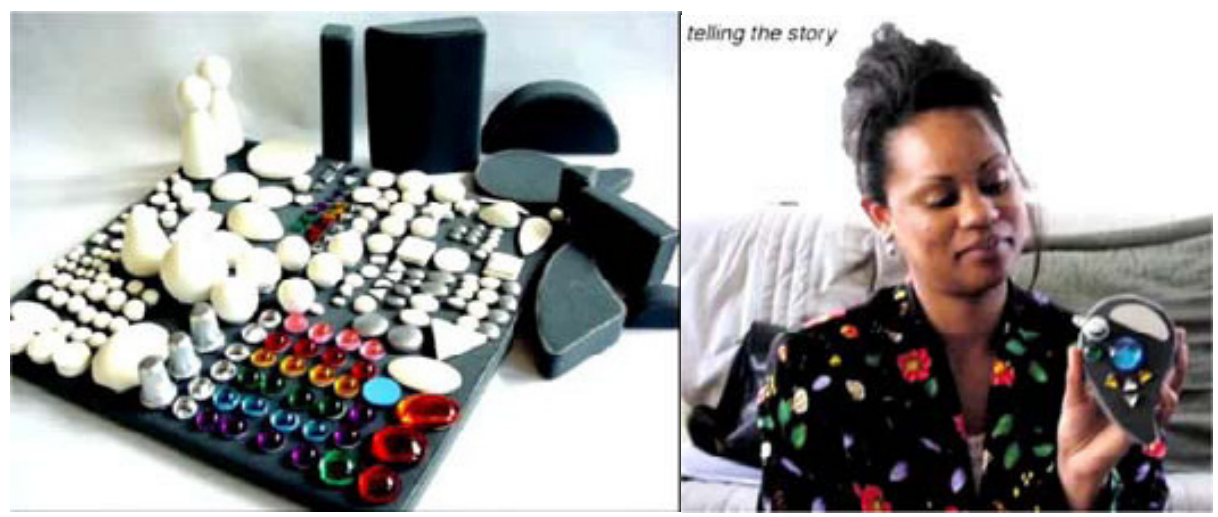

Fig. 7 E. Sanders. 2004. (Reproduced with permission). Co-design toolkit developed by Sanders.

Sanders refers (and to some extent legitimises her work) by drawing on the writings of Ivan Illich, in particular his book Tools for Conviviality (1973). However it is not clear if Sanders suggests that her toolkits are actually "tools for conviviality" or whether these are still to be invented in the future, or indeed if they already exist in other forms. There is perhaps an irony in Saunders' utilisation of Illich's theories because at the time of writing - the early 1970s there was a residue of optimism for social change and a belief in the political process. Illich envisages not mere tools for conviviality but a restructuring of our industrial culture, a "society-wide inversion of present industrial consciousness [...and] institutions" (Illich, 1973, Ch. II, p14). For Illich it is not merely inventing new tools but it is the mastery and control over these tools that needs to be addressed. Even if Sanders aligns herself with this Marxist spirit, in reality her work, interesting as it is, fuels the research process of a corporate culture, keen to capitalise on our inner dreams and creative fantasies.

Others have argued that these new convivial tools already exist in the form of interactive devises, networks and environments (Flichy, 2007). Perhaps laptops are convivial tools in the sense that they provide a relative freedom as to where we work, and allow us to combine and switch between 'work' and 'leisure', study and entertainment, connect us with others and so on. But certainly the means by which laptops are produced is by no means convivial, and the production of electronics has stimulated the industrialization of non-western countries in exactly the way in which Illich argued was to be avoided. The people that make the tools that, perhaps, liberate us, they themselves most definitely are not free.

It would be unfair to single out Sanders here for this critique. The point is that without a change in consciousness, tantamount to a real shift in world trade 
policies and industrial practices, we will remain on a path of unsustainable development and maintain the inequalities that go with it. Tools in themselves are not the issue, but it is the ideological constructions they are embedded in, which need to be questioned and evolved. Thus to return to all the examples of applied ethnographic methods given above we might query the motives behind the crossing of disciplinary boundaries and the adaptation of ethnography out with its traditional context. If this is merely at the will of commerce in pursuit of profit, we need to question if indeed this is beneficial appropriation or corporate exploitation.

\section{Ullapool and Intuitive Anthropology}

Although I identify with, and my training is in, a design discipline some of my work has been in the realm of public art. After being shortlisted for a project in 1998, I was invited to stay for an artist residency up in Ullapool, a small fishing village on the West coast of Scotland. At Ullapool the building of a new - and long overdue - High School had begun, and the local community committee had managed to secure $£ 100 \mathrm{~K}$ in lottery and matched funding for artists to develop art projects around the school. As is so often the case by the time this funding for art became available a large amount of building work on the school had already been completed. It was thus important to work quickly so that the work would be integral to the architecture rather than providing an 'add on' or 'stuck on' piece of art.

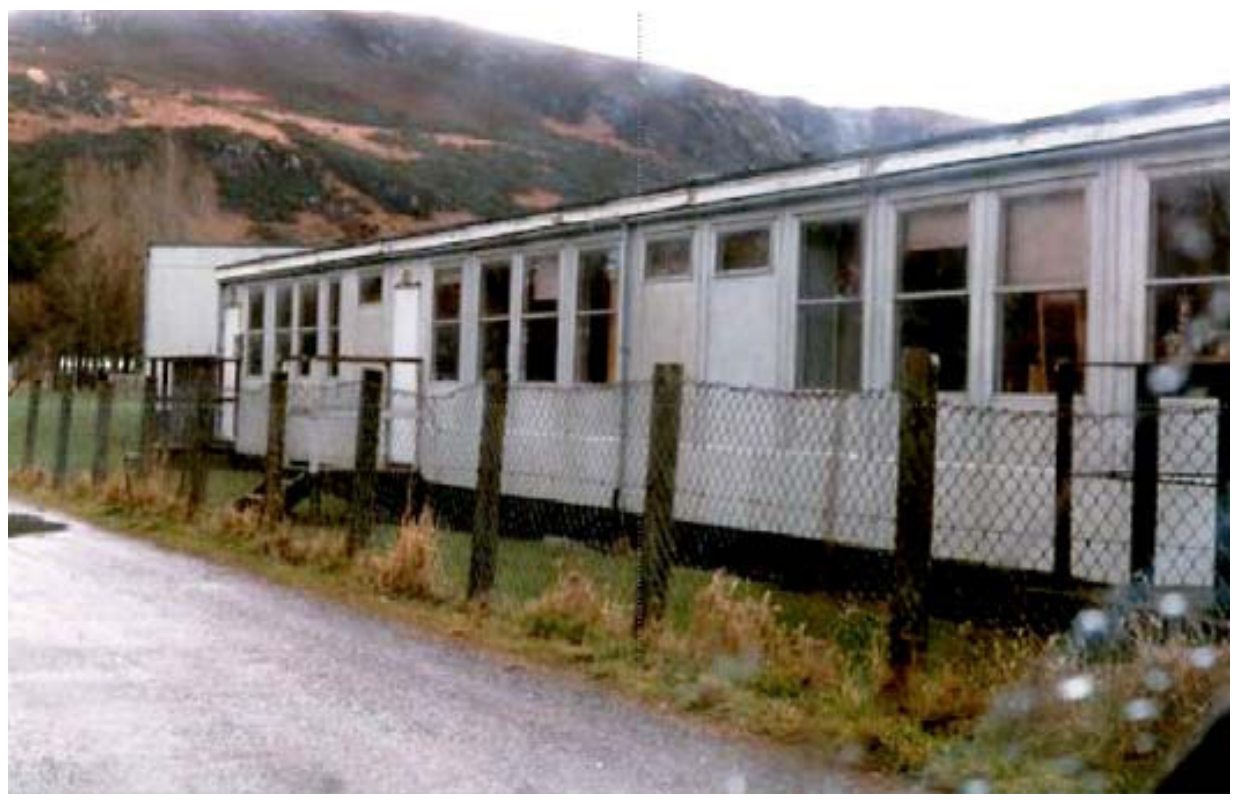

Fig. 8. VK\&C Partnership. 2000. For nearly 20 years the Ullapool high school was housed in 'temporary' portacabins. 


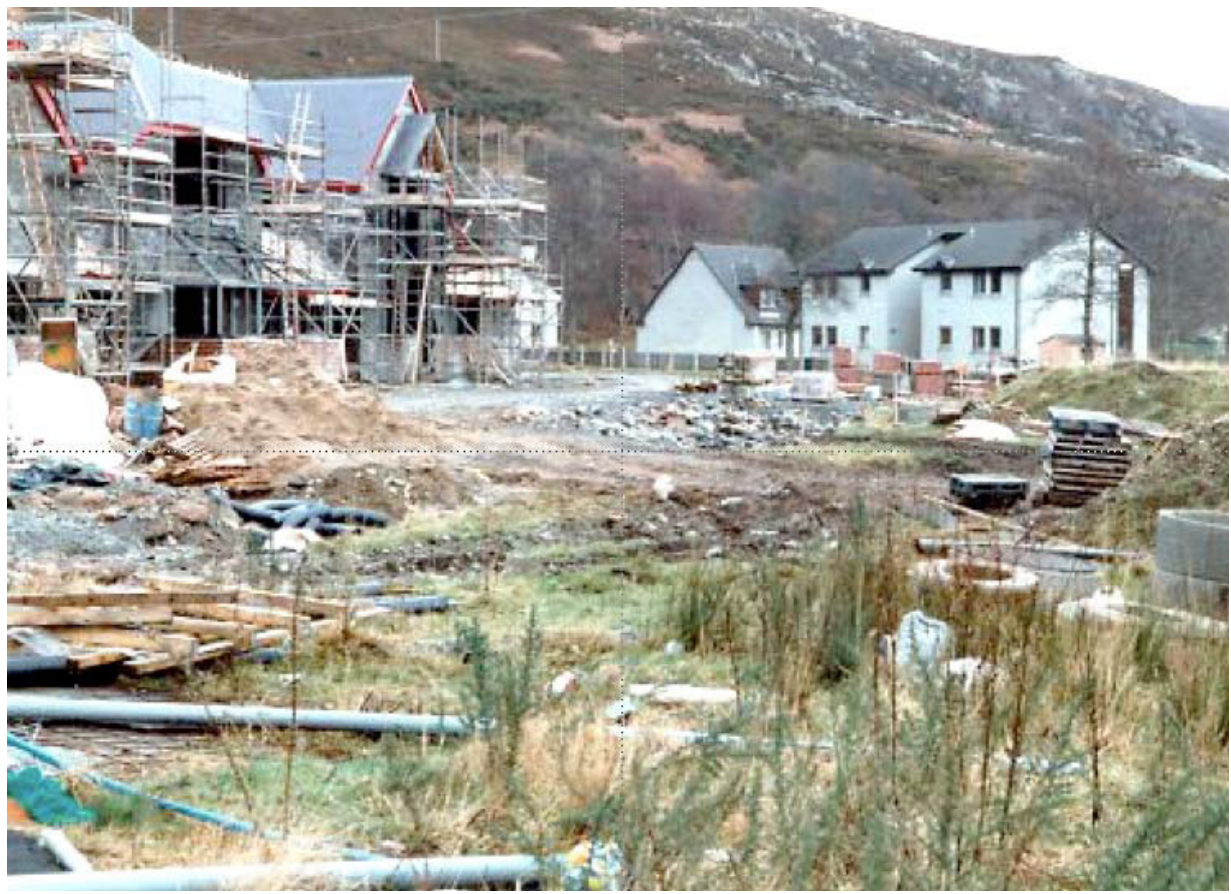

Fig. 9. VK\&C Partnership. 2000. The new high school under construction.

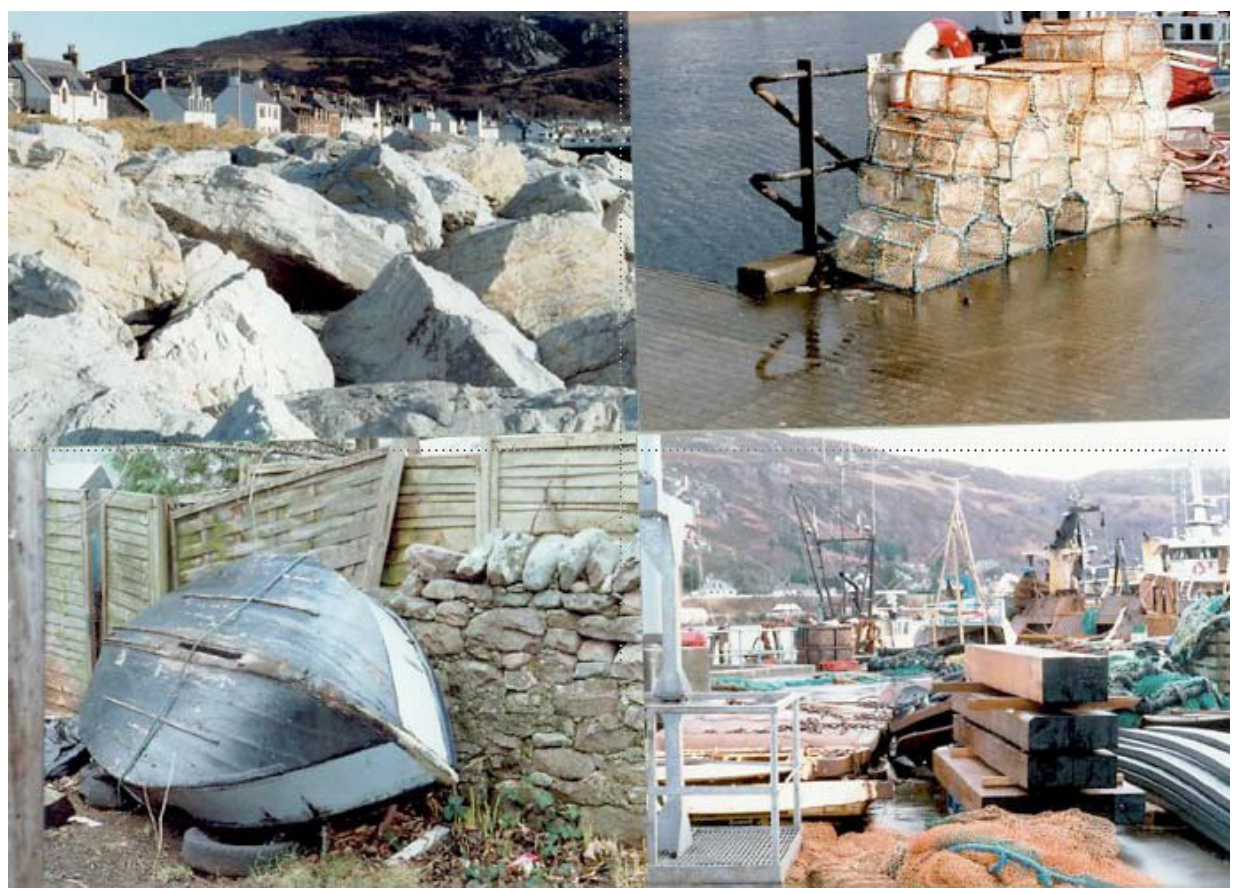

Fig. 10. VK\&C Partnership. 2000. Ullapool visual investigations. 
During my stay up there I was pleasantly surprised by how the community opened up to me - a complete stranger. I spent many evenings in the local pubs and, never short of a drink, gained instantly new friends, some of which I am still in touch with today. Though I have no formal training in ethnographic methodology I imagine that artist-in-residence programmes are not unlike ethnographic fieldwork.

During my stay I collected data, impressions, source material both from these social gatherings. I took many photographs (see Figure 10). I proposed to run a few workshops with some of the children that were about to move into the new school building. These were done with the help of the school's art teacher and took the form of free expression by means of discussions, drawings and small models used to visualise their ideas. The children were asked to express what Ullapool means to them and then how they might design a new school. They were encouraged to let their imagination go wherever it wanted and we got some wonderful ideas like slides and chutes coming off the roof, indoor fountains and swimming pools. They then made a number of drawings and sketches but were specifically encouraged to work with small models (see Figures 11 and 12).

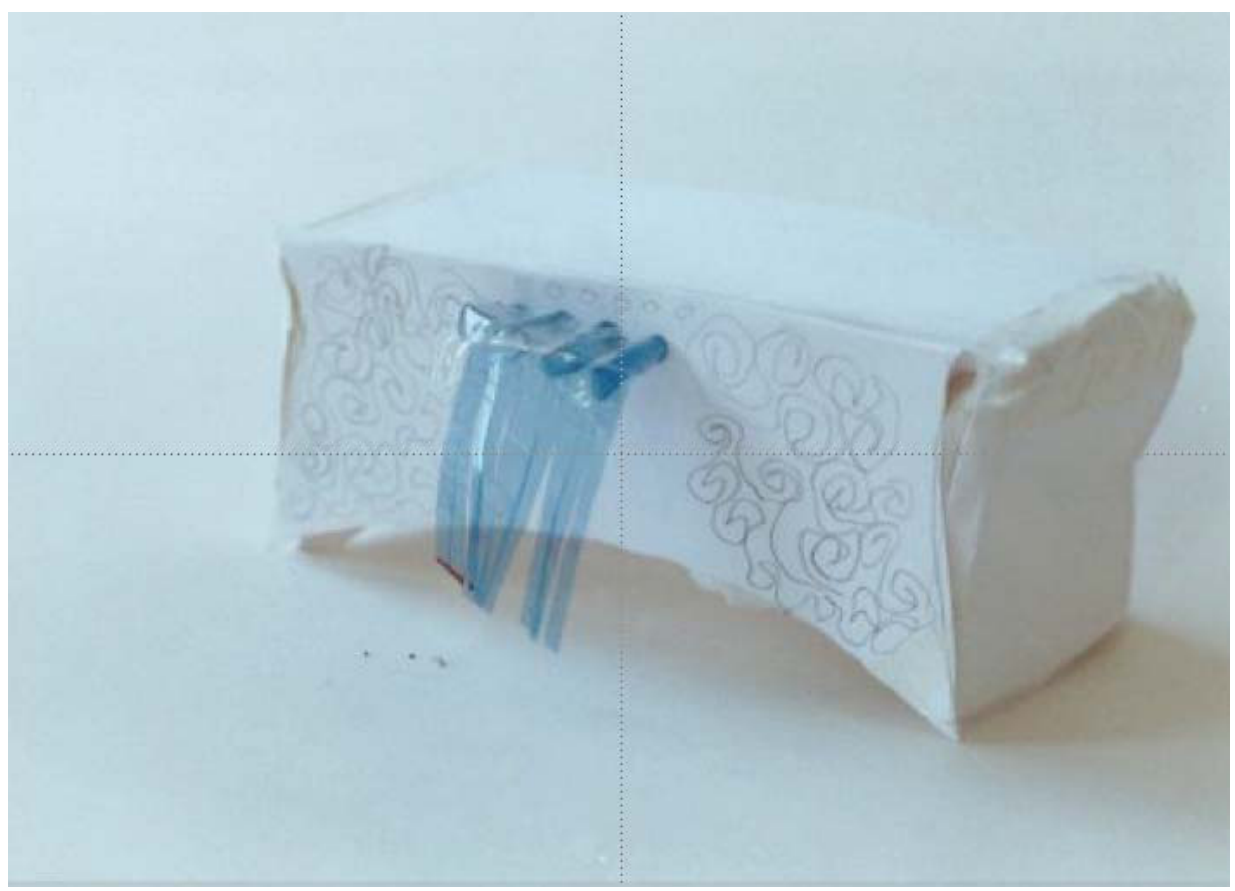

Fig. 10. VK\&C Partnership. 2000. Reception desk with waterfall, model by pupil. 


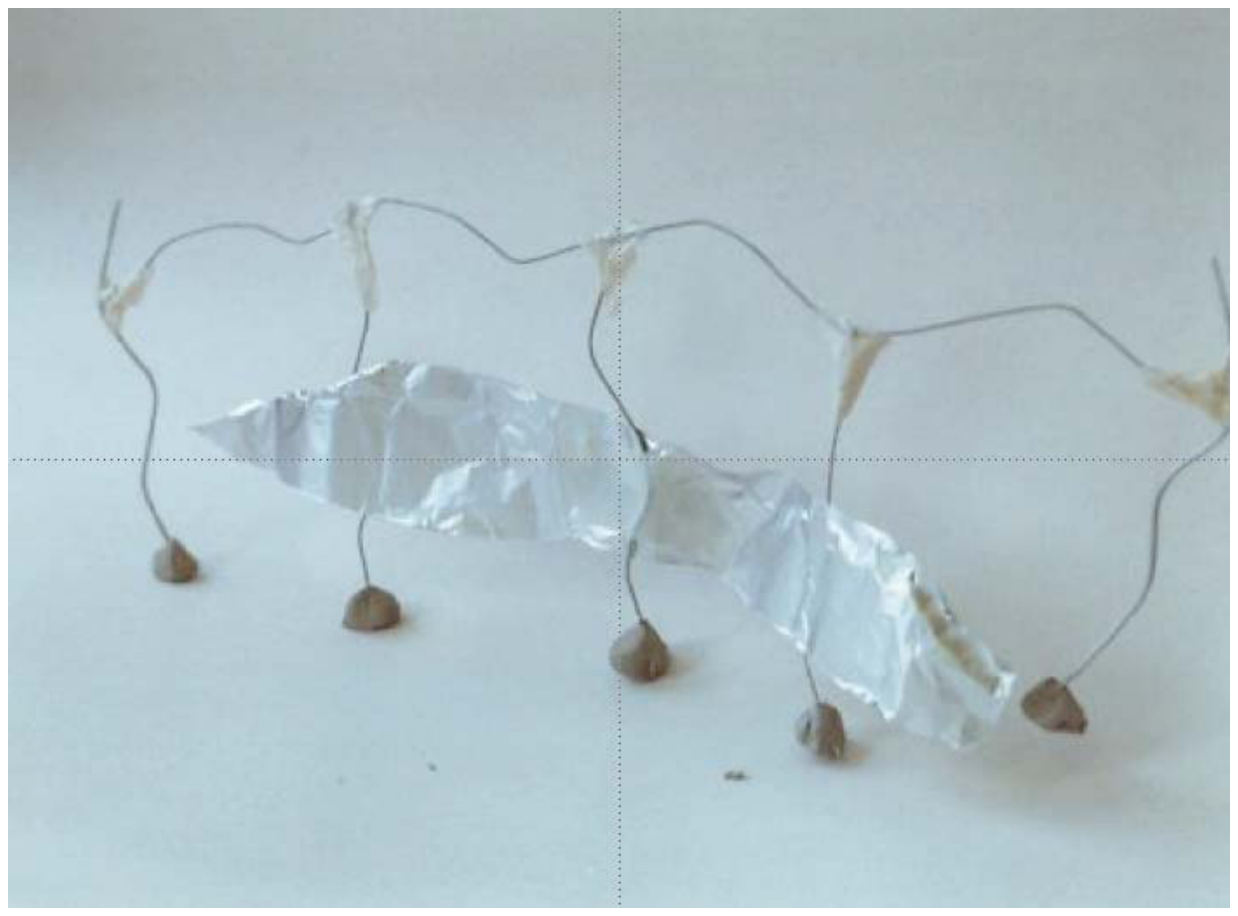

Fig. 11. VK\&C Partnership. 2000. Swimming fish railing, model by pupil.

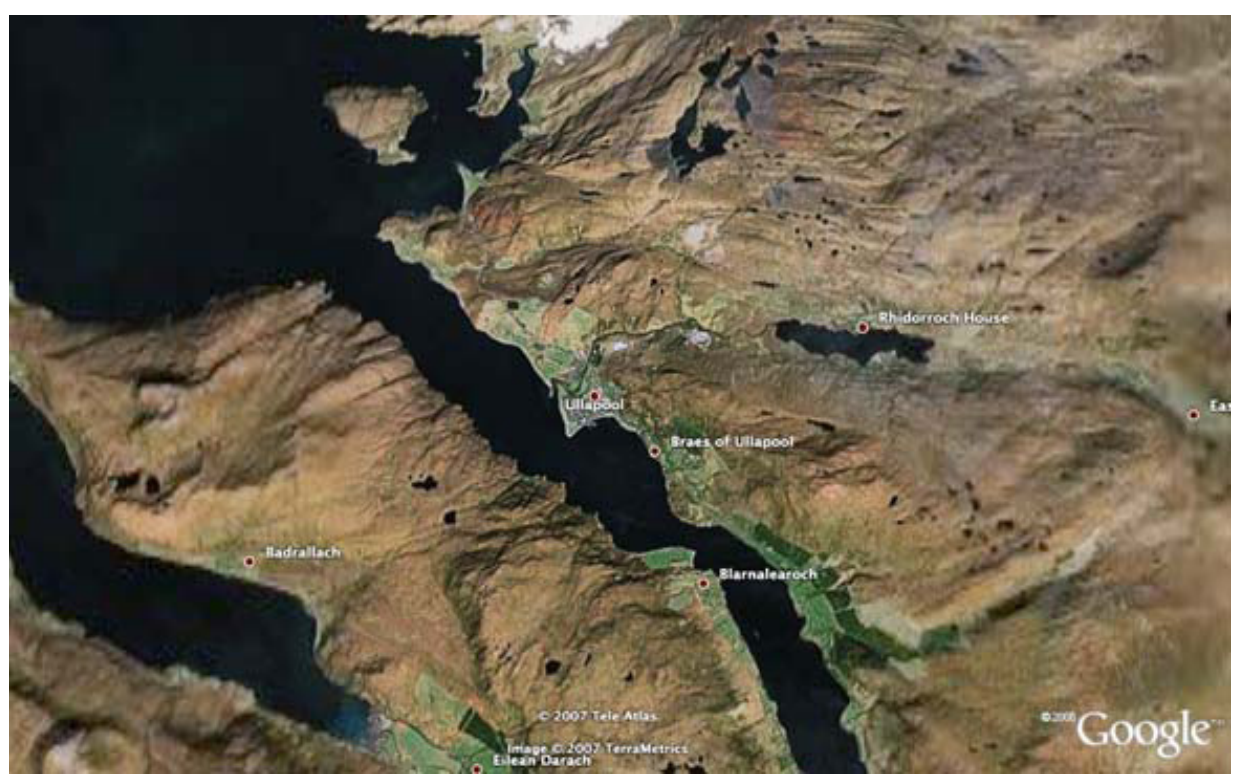

Fig. 12. Google Earth. Ullapool in its geographical setting. 
Much of the visual language that the children employed was inspired by the unique position of Ullapool: perched almost between water and land. The presence of water in the form of Loch Broom and the Atlantic Ocean dominates the landscape (see Figure 13). After subsequent visits to Ullapool I also began to understand its 'tidal' nature: in the winter Ullapool and its population contracts and its economy mainly revolves around commercial fishing. In the summer it expands to at least twice its size as it absorbs a huge number of tourists. Thus tides, cycles, flow and water became the themes underlying our proposals.

I brought back all the source material gathered in this way to the studio in Glasgow where I sat down with my partner and we would use these narratives, photos, sketches and models to generate ideas for art / design projects suitable for the school environment. I would then take these back up in the form of presentation boards and present them to the wider community of Ullapool by means of small exhibitions. We would note the feedback and develop ideas further after which I presented them to a committee of community representatives and other stakeholders: the Scottish Arts Council, the Highland Council, the school's architect and the contractors. Remarkably we navigated through this process, which was in a sense like designing by committee, but more accurately could be understood as a form of participatory design or designing by consensus. In this way of working the voices of all stakeholders are equally represented, it is the artist/designer's task to facilitate the dialogical process and, ultimately, synthesise the outcomes into a plan of action and implementation. (I do remember some anxious moments nearing the implementation stage of this project as we tabled new proposals for the landscaping around the building; we had to persuade the quantity surveyors to reconsider significant amendments to the existing bill of quantities.)

Information thus was gathered by the following means:

- Photographs of landscape and built environment

- Interviews and discussions

- Workshops

- Exhibitions and feedback sessions

- Committee meetings

This information gathering is a process we might call 'intuitive anthropology', which no doubt many artists will be able to relate too. Unlike the previously discussed contrast between a designer and ethnographer this way of working brings together the exploratory and non-closure approach of the ethnographer with the synthetic and goal orientated mindset of the designer. The ethnographic method here is employed to understand the relevant values and conceptions of the local residents and by finding visual correspondences allowing these to become encoded in the proposed art works. 
During the process of idea refinement and final implementation we identified a number of opportunities for pupils, parents, teachers and local businesses to get involved. For example - the outdoor furniture was designed by us but was manufactured by the Ullapool Boatbuilders, a small local company. They engaged a number of pupils to work with them in the construction, finishing and installation of all the seating and rubbish bins for the schools surrounding landscape. We found that this way of engaging the community in all the stages of the design process created a strong sense of involvement and ownership, resulting in a sense of appreciation and care for the final outcomes and an understanding of the symbolic language of the forms. It was also very transparent to them how the money was spent and how the pieces were made, where the materialshad come from and what processes and people were involved. The project allowed for the Ullapool residents to reflect upon and rethink their identity as derived from a sense of place. The final works installed are markers of this process and provide places and objects for contemplating Ullapool and its role in the 21st Century (see Figures 14-19).

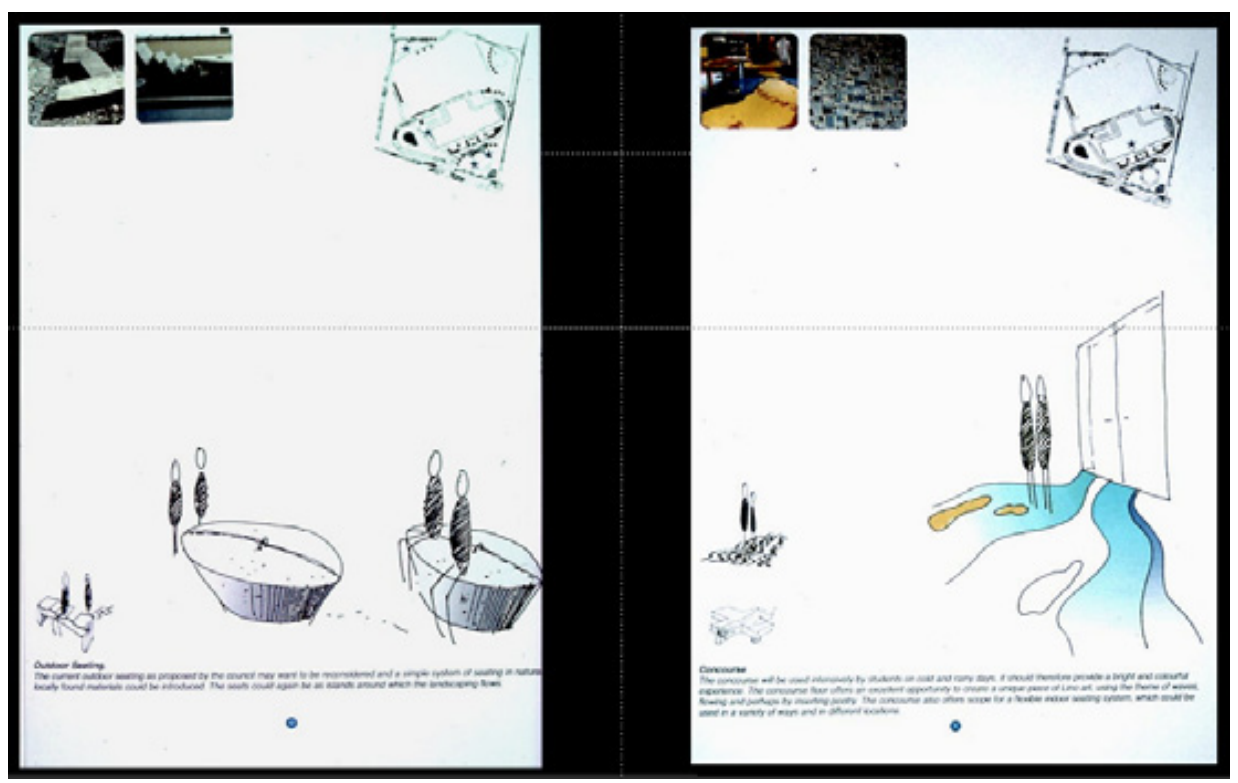

Fig. 13. VK\&C Partnership, 2000. Concept exhibition boards for seating and floor design. 
craft + design enquiry

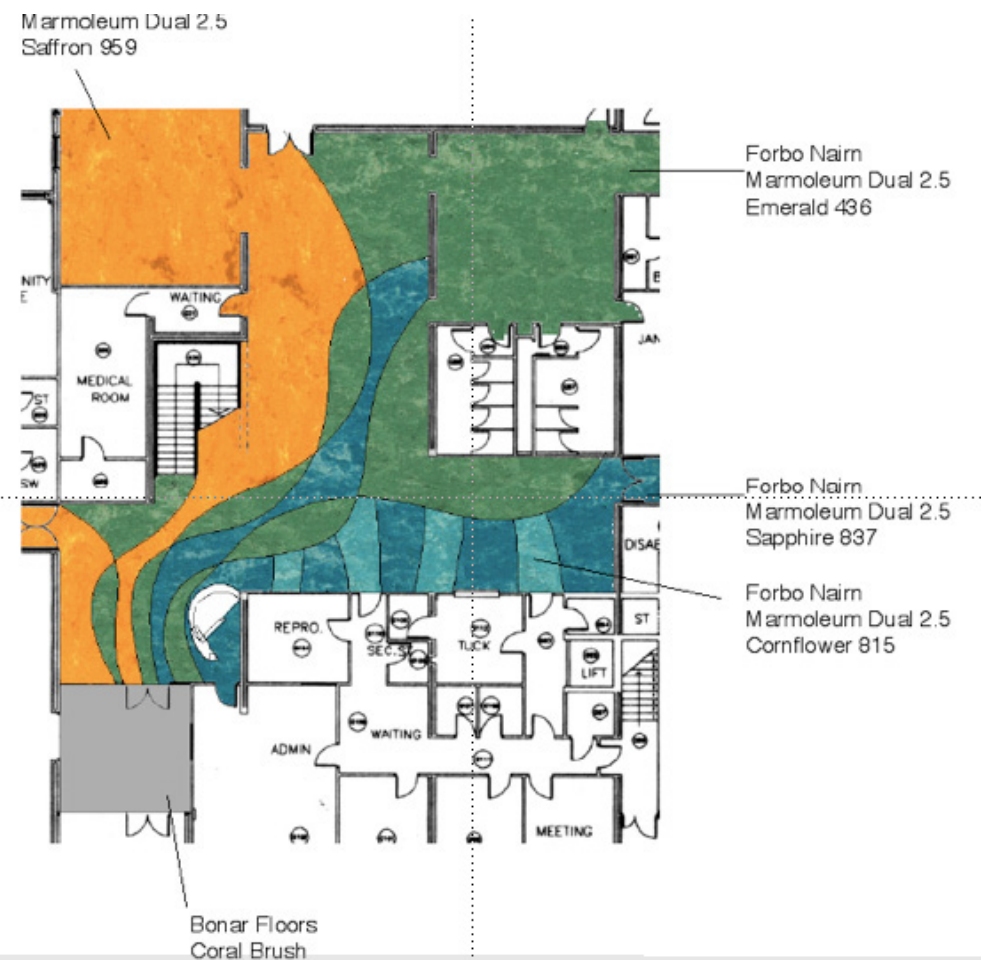

Fig. 14. VK\&C partnership, 2000. Implementation drawing for floor design. The lines are a symbolic representation of the flowing, tidal nature of Ullapool, its location between sea and land and of the local crofting plots which can be clearly identified in the surrounding landscape.

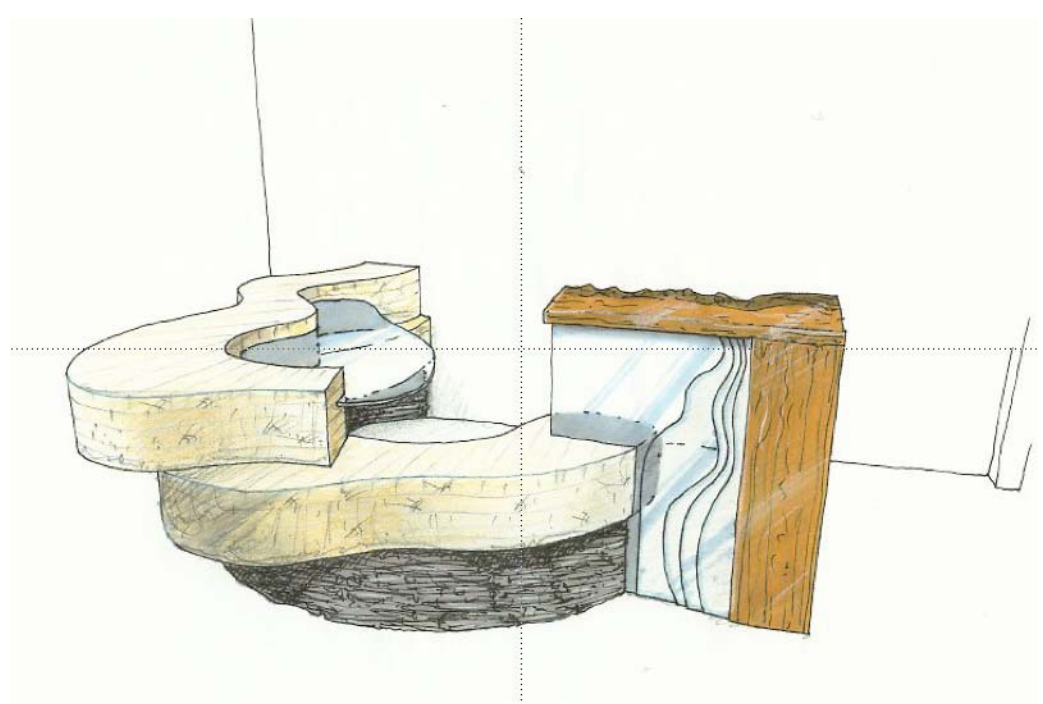

Fig. 15: VK\&C Partnership, 2000.Exhibition drawing for reception desk. Inspiration was taken from pupils' ideas, landscape and location. 


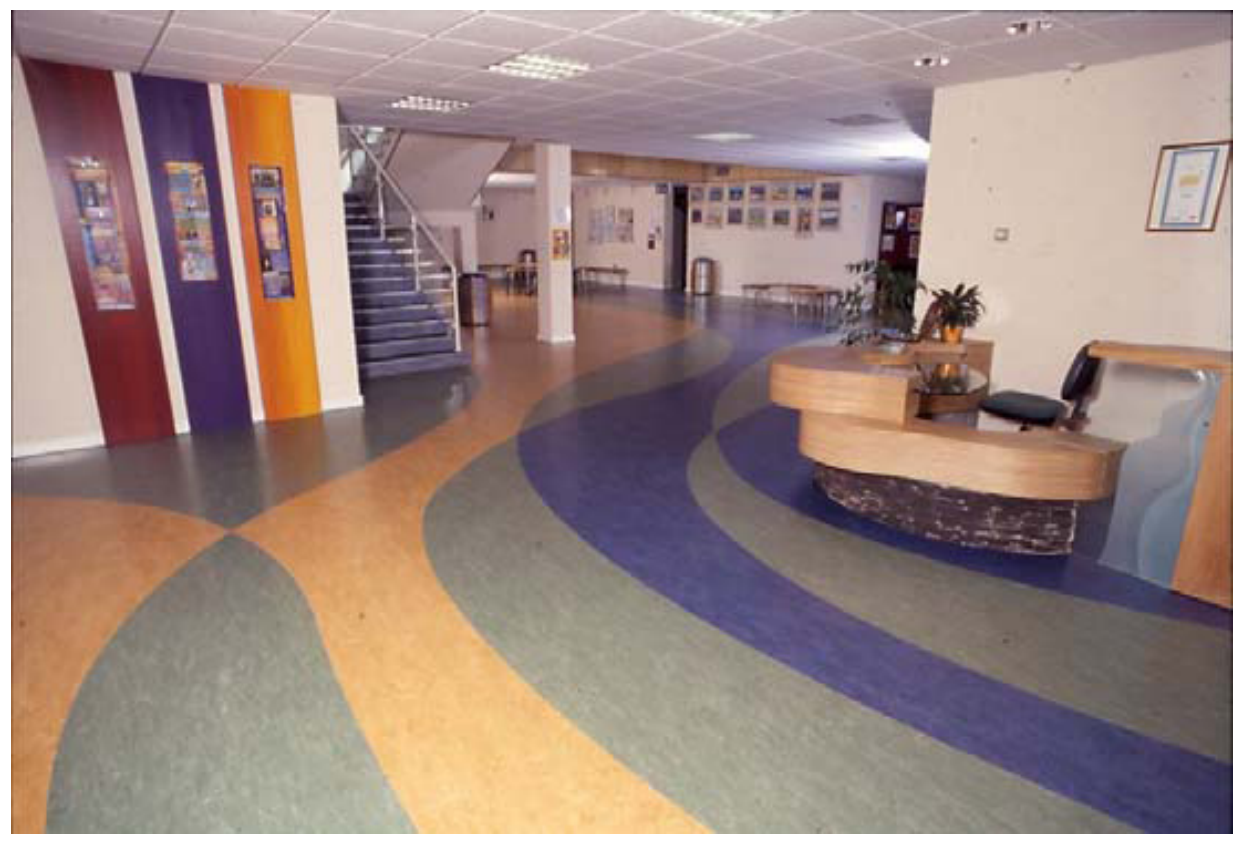

Fig. 16. VK\&C partnership, 2000. Finished floor and reception desk.

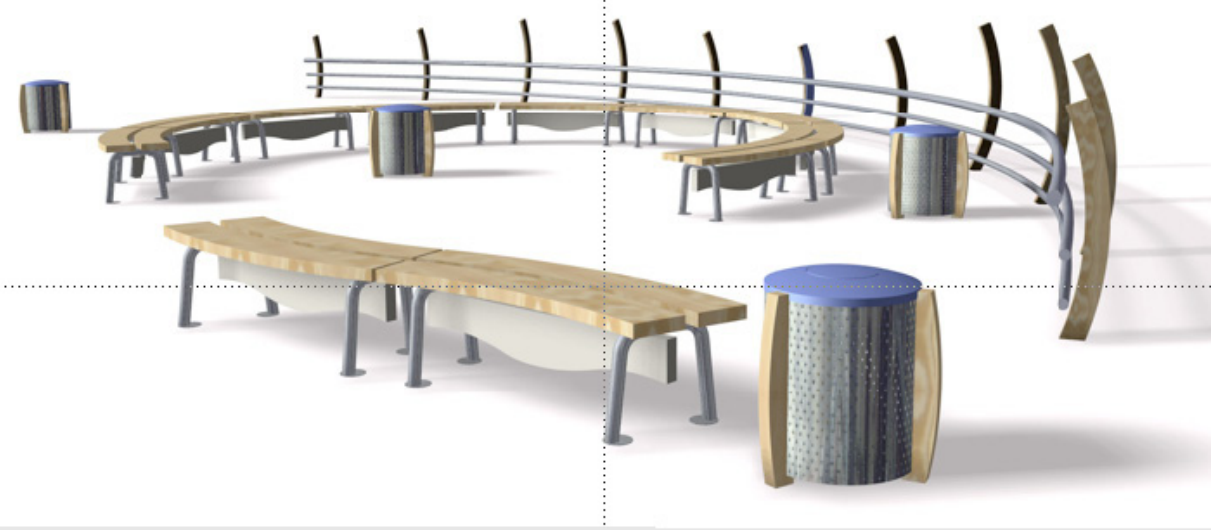

Fig. 17. VK\&C Partnership, 2000. Exhibition drawing showing outdoor seating, bins and railings around car park. The visual vocabulary is derived from nautical forms. 


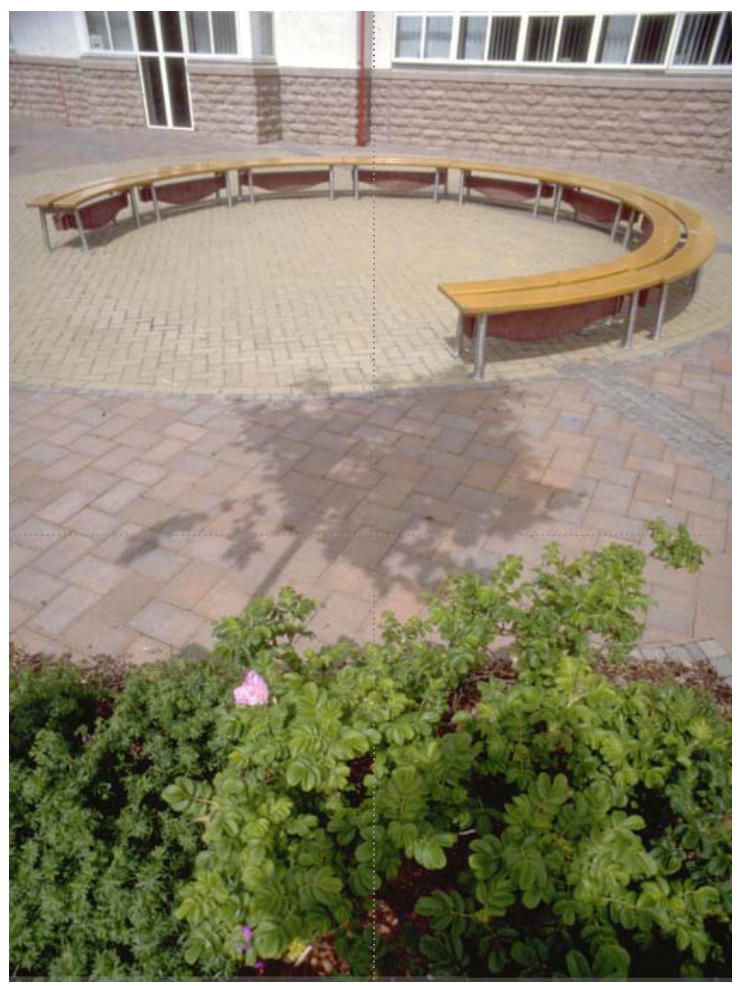

Fig. 18. VK\&C Partnership. 2000. Completed seating and landscaping.

\section{Conclusion}

Ethnographic research methods and anthropological analysis do appear to be part of a set of new migratory practices, and they are likely to embed themselves firmly into management, marketing and design practice, and subsequently education. What we need to be critical of is the level of popularisation and appropriation. Driven by management directives alone we are likely to see a similar exploitation as that which occurred in the beginning of the last century with the absorption of psychology into corporate culture (Ewen, 1996). As the goal of management driven strategies are generally short term and project based, a designer's ethnographic research may provide short term, commercial benefits. But, if aligned to management theory alone, ethnographic practice is unlikely to contribute to a more sustainable human future.

What I have attempted to do in this paper is to explore and, on occasion, critique how ethnographic methods have migrated into a diversity of commercial contexts related to advertising, marketing and design. I have also looked at an application within community art, and demonstrated how, used in this context, an ethnographic approach allowed for more community engagement and a sense of ownership, something difficult to achieve by other means. 
We could bemoan the loss of the traditional anthropological frameworks from which these methods originate and the superficiality and appropriation of these methods or techniques for the short term gain of a corporate culture, or even in the application of a community arts project. But perhaps also there is another side to this and research into people's behavioural motives may well provide us with an understanding of how to change our patterns of consumption to those that are more sustainable, and find ways in which we can uncover what truly fulfils us as human beings. For artists and designers anthropology has a wealth to offer when it comes to understanding the symbolic systems and discourses within which we as humans operate. It can aid our understanding as biological, symbolic and as aesthetic creatures, our relationship with nature and our contingency upon it.

\section{Illustrations}

Figure 1: Changes in the commercial process. A new breed of companies (e.g. Dell Computers) has emerged which assemble or manufacture products only after these have been ordered and paid for (Image VK\&C Partnership, 2006.)

Figure 2: Budweiser (left) promotes its Lite brand by depicting individuals in drinking scenarios, whereas Miller targets group drinkers by showing 'male bonding rituals'. (Images: Budweiser, Miller, 2007, no copyright infringement intended.)

Figure 3: Philips, 2004, (Reproduction permitted). Philips HomeLab. Temporary residents are observed while they test and comment on new electronic products.

Figure 4: Keep the Change, IDEO's innovative new bank account. (IDEO, 2006, no copyright infringement intended.)

Figure 5: Photo dairies illustrate the contrast between 'ordinary' car drivers and BMW owners. (No copyright infringement intended.)

Figure 6: The Future Laboratory. 2004. (Reproduced with permission.)After analysis of video ethnography many recommendations were made to Marks and Spencer for improvements to their retail environment.

Figure 7: E. Sanders. 2004. (Reproduced with permission.). Co-design toolkit developed by Sanders.

Figure 8: VK\&C Partnership. 2000. For nearly 20 years the Ullapool high school was housed in 'temporary' portacabins.

Figure 9: VK\&C Partnership. 2000. The new high school under construction.

Figure 10: VK\&C Partnership. 2000. Ullapool visual investigations. 
Figure 11: VK\&C Partnership. 2000. Reception desk with waterfall, model by pupil.

Figure 12: VK\&C Partnership. 2000. Swimming fish railing, model by pupil.

Figure 13: Google Earth.Ullapool in its geographical setting.

Figure 14: VK\&C Partnership, 2000. Concept exhibition boards for seating and floor design.

Figure 15: VK\&C partnership, 2000. Implementation drawing for floor design. The lines are a symbolic representation of the flowing, tidal nature of Ullapool, its location between sea and land and of the local crofting plots which can be clearly identified in the surrounding landscape.

Figure 16: VK\&C Partnership, 2000.Exhibition drawing for reception desk. Inspiration was taken from pupils' ideas, landscape and location.

Figure 17: VK\&C partnership, 2000. Finished floor and reception desk.

Figure 18: VK\&C Partnership, 2000. Exhibition drawing showing outdoor seating, bins and railings around car park. The visual vocabulary is derived from nautical forms.

Figure 19: VK\&C Partnership. 2000. Completed seating and landscaping.

\section{Bibliography}

Baudrillard, J. 1993, Symbolic Exchange and Death, London, SAGE.

Design Council, 2007, The design process, Eleven lessons: managing design in eleven global companies, available: http://www.designcouncil.org.uk/en/ About-Design/managingdesign/The-Study-of-the-Design-Process/

Design Management Institute, 1998, http://www.dmi.org/dmi/html/publications/ journal/pdf/18Defs.pdf Dodd, K. , 2001, Research and design success, Design Management Journal, Summer 2001. Available:

findarticles.com/p/articles/mi_qa4001/is_200107/ai_n8972939/pg_1

Ewen, S. ,1996, PR! A Social History of Spin. New York: BasicBooks, HarperCollins.

Flichy, P. , 2007, The internet imaginaire, MIT press, Cambridge, Mass.

Fine, G. A. , 1993, Ten lies of ethnography: Moral dilemmas of field research, Journal of Contemporary Ethnography, Vol. 22, No. 3, 267-294, Sage Publications. 
Gagliardi, M. ,2007, Looking out, looking in, and looking at: The world, yourself, and design, Tracing out a new taxonomy of the design process, Inform Lounge, issue 03, 2007. Availablehttp://www.mgstrategy.com/

Hemingway, T., 2006, Is the Internet convivial

Available: http://tryangulation.typepad.com/learning/2006/05/is_the_internet. html [accessed: 20/12/07] IDEO Website: http://www.ideo.com/portfolio/ re.asp?x=19006309 [accessed: 15/12/06

Illich, I. , 1973, Tools For Conviviality,Available:http://www.incae.ac.cr/ES/clacds/ proyectos/naciones_digitales/construyendo_escenarios/documentos/II lich\%20Chapters\%201_2_3.pdf

Ivey, M., 2005, 'The Scheme of Research: Forming to Function/ Functioning to Form', 4DED Proceedings of the Fourth Conference Doctoral Education in Design, ed. J. Girard \& D. Pijawka, Arizona State University.

Kelley, T. and Littman, J., 2001, The Art of Innovation, HarperCollins, London.

Krippendorff, K. and Reihhart B. (Eds.) 1989, Product Semantics. Design issues, 5(2).

McCracken, G., 2006, Intersection of Anthropology and Economics, http:// www.cultureby.com/trilogy/2006/05/_the_marketing_.html [accessed: 21/9/06]

Nussbaum, B. , 2006) Ethnography is the new Core Competence. Available:http:// www.businessweek.com/innovate/NussbaumOnDesign/archives/2006/02/ ethnography_is.html[accessed: 21/9/06]

Philips Research, HomeLab: Our testing ground for a better tomorrowhttp:// www.research.philips.com/technologies/misc/homelab/ [accessed: 21/9/06]

Raymond, M. , 2003, The tomorrow people: future consumers and how to read them, Prentice Hall, London.

Sanders, E.B. , 2002, Collective Creativity, Available:http://loop1.aiga.org/ documents/edition003/sandersucd/03_sandersucd.pdf

Sanders, E., and Dandavate, U. , 1999, Design for experiencing: New tools, In C. J. Overbeeke, and P. Hekkert (Eds), Proceedings of the first international conference on design and emotion (pp. 87-92). The Netherlands: TU Delft.

Sanders, E.B. , 2006, The market-driven era is finally giving way to the peopledriven era, Design Research Quarterly, September 2006, Design Research Society. Available: http://www.drsq.org/issues/drq1-1.pdf

Shaffer, D. , 2005, Homelab: Who will be voted off? Weblog available: http:// www.odannyboy.com/blog/new_archives/2005/11/ [accessed: 18/12/07] 
Skaggs, P. , 2005, Observational Research. Formalising Curiosity. Available: http://www2.uiah.fi/joiningforces/papers/Skaggs.pdf\#search=\%22ideo\%20 observational\%20research\%22[accessed: 21/9/06]

Stevens, T. , 1999, Lessons From The Leading Edgehttp://www.industryweek. com/CurrentArticles/asp/articles.asp?ArticlelD=582 [accessed: 21/9/06]

Tischler, L. , 2004, Every Move You Make. Available:http://www.fastcompany. com/magazine/81/everymove.html [accessed: 22/12/06]

The Future Laboratory (2003a), Ethnographic Workshop, Dundee 2003.

The Future Laboratory , 2003b , Marks and Spencer Briefing, see: http://www. futurelaboratory.com, [accessed: 14/9/06]

Wilson, B, IDEO and The Art of Innovation: The Role of Listening in Consumer Product Development Available: http://www.businesslistening.com/ideoproduct-innovation.php [accessed: 21/9/06] 